\title{
A ANCORAGEM MORAL DOS DIREITOS HUMANOS COMO OBSTÁCULO À IMPLEMENTAÇÃO DOS DIREITOS DAS MINORIAS
}

\section{Rogério Pacheco Alves ${ }^{1}$}

Resumo: O objetivo do presente trabalho é o de problematizar o fundamento moral enquanto plataforma de reivindicação e criação dos direitos das minorias, isto é, a ideia, largamente difundida, de que a força normativa dos direitos humanos vai buscar seu fundamento na moral. É que, para além de todos os problemas que uma abordagem moral dos direitos suscita, especificamente na esfera dos direitos das minorias é justamente a moral que vai representar o mais poderoso obstáculo à sua implementação. Isso porque: - a moral e os conceitos universais abstratos aos quais se conecta são barreiras epistemológicas; - muitos dos direitos das minorias encontram no corpo a sua plataforma de reivindicação, o que a moral interdita através de diversas estratégias de rebaixamento do corpo; - num ambiente neoliberal, o argumento do mérito, de cunho fortemente moral, é articulado com uma nova racionalidade que produz "subjetividades contábeis", ou seja, a concorrência sistemática entre indivíduos, a excluir boa parte dos grupos e indivíduos vulneráveis. Parte-se da premissa de que os direitos das minorias não são conquistas morais da humanidade, mas sim conquistas políticas de movimentos sociais que escrevem a história social dos direitos humanos, ou seja, a partir da constatação de que os direitos das minorias devem ser escritos e reescritos todos os dias, não são a priori morais. Enfim, cuida-se de contestar o estatuto legitimador da moral em si, para além das usuais discussões sobre redistribuição e reconhecimento. A metodologia consistirá na revisão bibliográfica sobre o tema

\footnotetext{
${ }^{1}$ Possui graduação em Direito pela Universidade Federal do Rio de Janeiro (1993), mestrado em Sociologia e Direito pela Universidade Federal Fluminense (2005), Pós-Graduação em Filosofia Contemporânea pela PUCRio (2009) e Doutorado em Teoria do Estado e Direito Constitucional pela PUC-Rio (2015). Professor adjunto da Universidade Federal Fluminense (UFF). É autor dos livros "O DNA Kantiano dos Direitos Humanos e sua Crítica a partir da Filosofia Imanente de Spinoza" e "As Prerrogativas da Administração Pública nas Ações Coletivas", publicados pela editora Lumen Juris. É co-autor do livro "Improbidade Administrativa", publicado pela editora Saraiva. Possui artigos publicados em livros e revistas jurídicas. Universidade Federal Fluminense (UFF), Rio de Janeiro
} http://buscatextual.cnpq.br/buscatextual/visualizacv.do?id=K4758676U4 E-mail: rogeriopacheco@uol.com.br 
e na análise de alguns dados empíricos, com incursões nos campos do direito, da filosofia do direito e da sociologia.

Palavras-chave: DIREITOS HUMANOS; MORAL; MINORIAS; VULNERÁVEIS.

\section{Sumário}

1. Introdução. 2. Os Direitos Humanos como Direitos Morais. 3. A Moral e os Conceitos Universais Abstratos enquanto Barreiras Epistemológicas no Campo dos Direitos das Minorias.

4. Estratégias de Rebaixamento do Corpo: Eugenia e Vidas Indignas de serem Vividas. 5. Subjetividades Contábeis. 6. Conclusão.

\section{Introdução}

A moral está em alta nos Tribunais, está com "o moral elevado". Mas há, em certos setores da sociedade, quem pense que não, quem veja a moral de forma enviesada, com desconfiança de seus anunciados benefícios. Setores da sociedade para quem a moral sempre foi um obstáculo de acesso a direitos.

Veja-se o caso do metaprincípio da dignidade da pessoa humana: de origem religiosa e medieval, seus modernos contornos kantianos, ou seja, a concepção de que o homem, por sua conatural racionalidade, jamais pode ser tratado como meio, senão como fim ("Age de tal maneira que uses a humanidade, tanto na tua pessoa como na pessoa de qualquer outro, sempre e simultaneamente como fim e nunca simplesmente como meio") $)^{2}$, tem também uma dimensão negativa, invocada não como plataforma de reivindicação de direitos e liberdades (dignidade como autonomia), mas justamente o oposto. Por exemplo, a invocação do conceito de dignidade

${ }^{2}$ Kant, Fundamentação da Metafísica dos Costumes, p. 229. 
humana como forma de fundamentar o recolhimento compulsório de usuários de crack $\mathrm{e}$ moradores de rua, na Cidade do Rio de Janeiro, a partir de 2009, como medida de "preparação estética" da Cidade para os megaeventos esportivos ocorridos em 2014 (Copa do Mundo) e 2016 (Olimpíadas). As verdadeiras e inconfessáveis razões eram de ordem urbanística e econômica, mas o metaprincípio fundamentador da dignidade da pessoa humana apareceu com facilidade nas falas públicas. Note-se o que dizia o então Secretário Municipal de Assistência Social do Município do Rio de Janeiro a propósito do "choque de ordem" instituído para retirar os “indesejáveis" das ruas da cidade:

\begin{abstract}
"O objetivo (...) ao propor a internação compulsória de usuários de crack é salvar vidas e devolver a dignidade perdida a pessoas ultrajadas socialmente, sob o domínio do vício das drogas. Fazer com que elas possam novamente sonhar, ter o direito a sorrir, poder acreditar no futuro, reconstruir-se como cidadãos

inseridos na sociedade, ser respeitadas como seres humanos. Quando o indivíduo perde a dimensão do decidir, cabe ao poder público suprir essa lacuna, estendendo-lhe a mão. (...)".3.
\end{abstract}

A partir de tais motes, o propósito do presente trabalho é problematizar a ancoragem moral dos direitos humanos no campo dos direitos das minorias, isto é, a ideia, largamente difundida, de que a força normativa dos direitos humanos vai buscar seu fundamento na moral. É que, para além de todos os problemas que uma abordagem moral dos direitos suscita, especificamente na esfera dos direitos das minorias é justamente a moral que vai representar o mais poderoso obstáculo à sua implementação. Isso porque:

- a moral e os conceitos universais abstratos aos quais se conecta (como o conceito moral de dignidade da pessoa humana) são barreiras epistemológicas;

- muitos dos direitos das minorias encontram no corpo a sua plataforma de reivindicação, o que a moral interdita através de diversas estratégias de rebaixamento do corpo. No caso brasileiro, indo além, há ainda uma forte influência das linhagens eugenistas do início do século passado, a formar classes de pessoas indignas;

\footnotetext{
${ }^{3}$ Fala do então Secretário Municipal de Assistência Social do Município do Rio de Janeiro, em 26/10/12. In: http://rodrigobethlem.blogspot, acessado em 06/10/14.
} 
- num ambiente neoliberal, o argumento do mérito, de cunho fortemente moral, é articulado com uma nova racionalidade que produz "subjetividades contábeis", ou seja, a concorrência sistemática entre indivíduos, a excluir boa parte dos grupos e indivíduos vulneráveis.

Antes de ingressarmos propriamente em cada um desses elementos, é o caso de verificar, rapidamente, a relação entre direitos humanos e moral, nosso próximo tema.

Faz-se necessário esclarecer também, desde logo, que para os fins ora propostos adotamos o conceito de minorias a partir dos critérios de diferença (determinadas características que diferenciam determinadas pessoas da sociedade em geral); diversidade (o direito de ser diferente, tanto de grupos quanto de indivíduos, em relação à sociedade majoritária e também

entre os próprios grupos minoritários e vulneráveis); subjugação (exclusão, total ou parcial, de um determinado grupo da participação ativa nas relações de poder, o que gera uma posição hierárquica inferior na sociedade); vulnerabilidade (situação em que pessoas estão em uma posição na qual podem ser atacadas, ofendidas, feridas, o que pode surgir de circunstâncias naturais ou de arranjos sociais); e pertencimento a um grupo social (definição não a partir da percepção do indivíduo como pertencente a um grupo, mas sim a partir da perspectiva do agente de perseguição, donde surge a necessidade de tratamento e proteção diferenciados) (JUBILUT, 2013, pp. 13-21). ${ }^{4}$

\section{Os Direitos Humanos como Direitos Morais}

\footnotetext{
${ }^{4} \mathrm{O}$ critério quantitativo já foi abandonado pela literatura sobre o tema. Não incorporamos ao conceito de minorias o critério de identidade, isto é, o conjunto de atributos e características que permitem a individualização das pessoas na sociedade, que surgem de nosso "pertencimento" a culturas étnicas, raciais, linguísticas, religiosas e nacionais, tendo em vista o seu caráter problemático, sobretudo o problema sobre o protagonismo na formação da identidade (por quem a identidade é formada, pelo grupo ou pelo indivíduo?), o forte risco da criação de separatismos e enclausuramentos e o problema da pluralidade de identidades, ou seja, a ampla possibilidade de combinação, por exemplo, das variáveis gênero, raça e orientação sexual, a gerar muitos resultados (mulher, negra e homossexual; homem, negro e heterossexual; mulher, branca e heterossexual; homem, branco e homossexual; mulher, negra e heterossexual; homem, negro e homossexual etc).
} 
Tem sido fomentado um certo consenso no sentido de que os direitos humanos são direitos morais, ou seja, direitos positivados pelo legislador (constitucional ou mesmo supranacional) que possuem uma fundamentação externa, uma justificação legitimadora que encontra ancoragem na moral. Não são, assim, apenas coercitivos (alguns sequer serão) e não valem apenas porque derivam de uma autoridade legitimada pelo direito a criá-los (o legislador democrático). Valem - aqui o plus- porque encontram fundamento na moral, que atua, portanto, como filtro que confere legitimidade a tais direitos e os tornam universalmente aceitos.

Disso decorre uma zona de indiscernibilidade entre direito e moral, certamente. Nessa linha, Carlos Nino, ao indagar sobre o fundamento da obediência ao direito sustentará que, dada a insuficiência do princípio da autoridade ("devemos obedecer as leis editadas pela autoridade competente"),

“(...) llegará un punto en que debemos aceptar que una norma jurídica es aceptada en virtude de un juicio normativo que no es una norma jurídica, puesto que no es a su vez aceptado por haber sido formulado por una autoridade que otro juicio normativo legitima sino por sus próprios méritos. Ahora bien, un juicio normativo que es aceptado no por haber sido formulado por certa autoridad sino por sus próprios méritos, es precisamente lo que suele identificar como un juicio moral - en esto consiste precisamente el rasgo de autonomia de los juicios morales enfatizados por Kant.

Con esto tenemos la conclusión aparentemente paradójica de que las normas jurídicas se identifican como tales por su derivación en el razionamento práctico de juicios de índole moral. Si un juicio que deriva lógicamente de un juicio moral también lo es, de aqui se sigue que las normas jurídicas, entendidas como proposiciones justificatorias, son un caso especial de juicios morales" (NINO, 1990, p. 320).

Para o autor argentino, os princípios morais que fundamentam o direito são a autonomia, entendida como a impossibilidade de gestão alheia dos planos de vida livremente eleitos pelo indivíduo (livre-arbítrio), desde que não afetem a vida de terceiros; a inviolabilidade, que consiste em tornar inexigíveis sacrifícios e privações que não redundem em benefício aos indivíduos (o combate aqui é sobretudo contra o utilitarismo e o coletivismo); e a dignidade, que estabelece que "as pessoas devem ser tratadas de acordo com suas decisões, intenções e expressões de consentimento" (em oposição ao determinismo), que seriam os "antecedentes de obrigações e responsabilidades" (NINO, 2011, p. 233). 
Habermas, a seu turno, dirá que o princípio da dignidade humana desempenha o papel de fonte moral dos direitos fundamentais em razão da existência de contextos culturais diferentes, nos quais os universais facilitam as negociações de acordos e a construção de consensos sobrepostos, como se deu, por exemplo, por ocasião da fundação das Nações Unidas. Por outro lado, os direitos humanos precisam o substrato normativo da igual dignidade e a denominada "função heurística" da dignidade humana serve de chave para entender as conexões lógicas entre as gerações de direitos humanos (direitos liberais, direitos de participação, direitos sociais/culturais). Daí que o conceito de dignidade fundamenta a indivisibilidade das categorias dos direitos humanos e cria uma relação de colaboração recíproca como pressuposto ao

cumprimento da promessa moral de respeitar por igual a dignidade de cada pessoa (HABERMAS, 2010, p. 7-9).

Para Habermas, a dignidade humana configura o portal através do qual o substrato igualitário e universalista da moral se traslada ao âmbito do direito e daí decorre a conversão da promessa moral de igual respeito a todo ser humano em moeda legal, conversão que revela a dupla face dos direitos humanos, vale dizer, seu conteúdo moral e, ao mesmo tempo, sua forma de direitos subjetivos. Em suma, os direitos humanos, via dignidade humana, são uma parte da moral que pode ser traduzida ao âmbito da lei coercitiva e transformada em uma realidade política e também o produto de uma "síntese inverossímil" entre a moral internalizada, justificada racionalmente e ancorada na consciência individual (Kant), e o direito promulgado e coercitivo do Estado moderno e de suas instituições (HABERMAS, 2010, pp. 10-11).

Nino e Habermas situam-se na linhagem kantiana, que na Metafísica dos Costumes (1797) aproxima direito e moral, ou seja, o conceito de direito em Kant passa a gozar de uma igual importância frente à moral, diferentemente do que ocorria na Fundamentação da Metafísica dos Costumes (1785), em cujo texto aparece tão somente o imperativo categórico da moral. Como raiz comum de ambos Kant aponta a noção de obrigação, que faz da ética e do direito domínios conexos e pertencentes à "moral", muito embora mantenha-se a distinção entre ética e direito através do critério do engajamento da subjetividade: no campo da ética, tendo em consideração 
o propósito ou motivo da ação; no âmbito do direito, relativamente apenas à ação exterior e suas consequências. ${ }^{5}$

Para Kant o direito é o conjunto das condições de uma vida em conjunto de acordo com uma lei universal da liberdade ("age exteriormente de modo que o livre uso de teu arbítrio possa se conciliar com a liberdade de todos, segundo uma lei universal"). Assim, a justiça da ação pressupõe o respeito à liberdade de todos a partir de uma máxima de liberdade universal, o que constitui o princípio universal do agir jurídico e serve à aferição da justiça das ações e da própria legislação. Bem analisada, a lei universal do direito é construída por espelhamento ao imperativo categórico moral (“Age apenas segundo uma máxima tal que possas ao mesmo tempo querer que

ela se torne lei universal"), ${ }^{6}$ mais precisamente no ponto em que correlaciona a ação jurídica ao critério de aferição universal. Há uma mesma estrutura formal, o que leva Otfried Höffe a sustentar a existência de um imperativo categórico jurídico:

"O conceito kantiano de Direito implica (...) um critério pelo qual todas as leis positivas são julgadas a respeito da sua legitimidade. São racionais ou inteiramente legítimas apenas aquelas prescrições jurídicas que garantem, conforme leis estritamente universais, a compatibilidade da liberdade de um com a liberdade de todos os outros. Este critério constitui, na esfera da Doutrina do Direito, o verdadeiro equivalente do imperativo categórico na Ética (Doutrina da virtude). Ele obriga a comunidade de liberdade externa a cumprir a legalidade universal do mesmo modo que o imperativo categórico obriga a vontade pessoal a cumprir as máximas auto-impostas" (HÖFFE, 2005, pp. 239-240).

A tese da existência de um imperativo categórico do direito superaria a visão de que as leis jurídicas, por serem heterônomas, se amoldam apenas aos imperativos hipotéticos e o próprio

\footnotetext{
${ }^{5}$ Em Kant, a distinção é estabelecida da seguinte forma: "Essa legislação que faz de uma ação um dever, e também faz deste dever um motivo, é ética. Porém, a legislação que não inclui o motivo do dever na lei e, assim, admite um motivo distinto da idéia do próprio dever, é jurídica" (KANT, 2003, p. 71).

${ }^{6}$ Fundamentação da Metafísica dos Costumes, p. 223. O próprio Kant fornece algumas variações do imperativo: "Age como se a máxima da tua ação se devesse tornar, pela tua verdade, em lei universal da natureza" ou "Age segundo máximas que possam simultaneamente ter-se a si mesmas por objeto como leis universais da natureza" (Fundamentação da Metafísica dos Costumes, pp. 224 e 236).
} 
conceito de justiça, mais amplamente, passa a ser um imperativo categórico (HÖFFE, 1991, p. $66)$.

Especificamente sobre as vantagens da adoção do conceito de imperativo categórico no Direito, Höffe é enfático:

\begin{abstract}
“(...) independentemente de todas as outras distinções políticas e culturais, estamos aqui convencidos de que a cada homem são devidos direitos fundamentais inalienáveis, por exemplo, o direito ao corpo e à vida ou a liberdade de crença e de consciência; um ordenamento jurídico em que tais direitos são feridos, nós o consideramos, ao contrário, como abertamente injusto e como incondicionalmente precisando de reformas.

Se pensarmos nos imutáveis direitos do homem, então aquilo que facilmente é objetado à ética do imperativo categórico de Kant, seu rigorismo, é convertido em sinal positivo. Ao menos na esfera do direito, tornou-se evidente que certas obrigações, justamente os inalienáveis direitos humanos, são válidas sem exceção. A ideia que o positivismo jurídico ou o empirismo jurídico silenciosa ou expressamente representa, isto é, que somente existem obrigações hipotéticas, se mostra aqui como falsa e um imperativo jurídico categórico resta como conceito adequado" (HÖFFE, 1991, p. 67).
\end{abstract}

Ora, se assim é, o imperativo categórico jurídico fornece uma medida às pretensões asseguradas pelo direito positivo e abre uma dimensão fundacional moral, a dimensão de existência de direitos pré e suprapositivos, a que chamamos de direitos humanos.

Mas é preciso desconfiar das "vantagens" apontadas por HÖFFE, diante dos comportamentos desviantes das minorias, seus "defeitos congênitos" e suas linhas de fuga nada convencionais, enfim, seus agenciamentos "anormais" que dificilmente se encaixarão nos moldes formais e extremamente rígidos do imperativo categórico jurídico-moral. Passemos ao próximo ponto.

\title{
3. A Moral e os Conceitos Universais Abstratos enquanto Barreiras Epistemológicas no Campo dos Direitos das Minorias
}

Fixadas as relações entre direitos humanos e moral, é pertinente agora verificar o quanto o argumento moral significa uma barreira epistemológica. 
Inicialmente, é o caso de reconhecer, como soa intuitivo, que problematizar a ancoragem moral dos direitos fundamentais nos inscreve na tradição crítica do direito, não com a pretensão de formulação de uma nova teoria dos direitos humanos nem tampouco como uma tentativa de sua desqualificação, mas, antes, na perspectiva da problematização, da desconstrução e da reformulação de alguns de seus conceitos fundamentais. Sendo o conhecimento uma expressiva intervenção no real, e não uma mera representação, trata-se de refutar a neutralidade do pensamento, a separação entre teoria e prática e de produzir análises que sejam social e politicamente engajadas, o que teorias fundadas em categorias abstratas não são capazes de dar conta.

De fato, todas essas pretensões críticas são interditadas pela abordagem moral dos direitos, que abandona a experiência do mundo sensível para encastelar-se numa racionalidade que cria uma liberdade conquistada a partir do cumprimento de rigorosos deveres morais. Por exemplo, em Kant, engenheiro da mais poderosa filosofia moral até hoje concebida, o homem habita, ao mesmo tempo, o mundo sensível da natureza e dos afetos, em que não é autônomo, e o suprassensível da razão, em que adquire autonomia. Também em Kant encontra-se a tese de uma finalidade moral no homem, ou seja, uma antropologia do homem moral que convive com a ideia de um destino moral da espécie humana. Em certa medida, a concepção kantiana se aproxima da visão de Rousseau do homem como um ser dotado da capacidade de aperfeiçoar-se, uma concepção por certo otimista. Em sua filosofia, a perfectibilidade aparecerá na forma de um destino moral da espécie humana e na capacidade que cada homem tem de dar-se os seus próprios fins (autonomia) em virtude da liberdade racional de cada um.

Contudo, o a priori das regras morais, o seu "já-dado", bloqueia a experiência, inimiga de tudo o que a moral pretende ser (a-histórica, atemporal). Ao fazê-lo, impede o conhecimento, que brota dos encontros que travamos com outros corpos nas teias da imanência, e não da transcendência. Isso ocorre num modelo moral substancialista (como o modelo prescritivo do decálogo) mas aparece também no caso do imperativo categórico moral kantiano, que é pura forma (“Age apenas segundo uma máxima tal que possas ao mesmo tempo querer que ela se torne lei universal') e que, por isso mesmo, inverte a relação de dependência da lei ao Bem (o contrário é o que se dá, o Bem passa a depender da pura forma da lei). Como dirá Deleuze, isso significa que a lei moral kantiana não tem mais que se fundar num princípio superior do qual 
tiraria o seu direito (o Bem), ela vale por si mesma e se funda em si mesma. Disso resulta que seu objeto - e também o objeto do direito-moral - se esquiva a todo momento, seu objeto é inapreensível (DELEUZE, 1983, pp. 90-91).

De notar-se que a lei moral pode até ser necessária e é possível que os mandamentos estejam bem fundados, mas a moral não dá nada a conhecer (seja no modelo substancialista, seja no modelo procedimental kantiano) e a lei é sempre a instância transcendente que determina a oposição dos valores bem/mal (DELEUZE, 2002, pp. 30-31).E, se assim é, a lei moral é da ordem da passividade e do erro, jamais do conhecimento, que requer uma postura de desobediência e uma certa "rebeldia". Ou, como afirmará Spinoza, “as coisas que são boas só por mandamento e convenção, ou porque simbolizam algum bem, não podem contribuir para a perfeição do nosso

entendimento e não passam de meras sombras" (SPINOZA, 2008, p. 71).

No campo do direito o a priori da moral vai encontrar espelhamento no dever-ser, que também se funda no abstrato e não na experiência. Daí se segue que a atitude dos juristas resulta de as noções de direito serem sempre apresentadas e tratadas fora de um contexto social preciso: o jurista não nega a existência e o peso das estruturas sociais, subordina-as ao seu sistema de pensamento. As ideias se tornam o fundamento da realidade e o jurista tem a necessidade de passar pela abstração para explicar a realidade. O resultado é um universalismo a-histórico (os termos abstratos deixam de pertencer à sociedade que os produziu) e daí decorre "o pluralismo de explicações", ou seja, a validade de vários pontos de vista (MIAILLE, 2005, p. 47-62). Além disso, o idealismo jurídico nos faz imaginar a existência de uma teoria e de uma prática enquanto campos distintos e por isso o jurista "sofre" diante das perplexidades que brotam do real, tenta explicá-las, de forma simplória, a partir da linguagem própria da lei, de seu código binário (lícito/ilícito), como se o real pudesse dobrar-se ao dever-ser. O problema é que o dever-ser não existe, só o ser existe, e o ser, ou seja, o real que o direito tenta apagar, possui muitas faces.

Um exemplo pode ilustrar tudo isso. Em 2013, o Governo Federal, por pressão da bancada religiosa do Congresso Nacional, suspendeu a divulgação de um importante material educativo elaborado pelos Ministério da Saúde e da Educação em parceria com a Organização das Nações Unidas para a Educação, a Ciência e a Cultura (Unesco), o Fundo das Nações Unidas para a 
Infância (Unicef) e o Fundo de População das Nações Unidas (UNFPA), que tinha por escopo fomentar o combate à homofobia e que fazia parte do programa de prevenção de doenças sexualmente transmissíveis (DST) e Aids. ${ }^{7}$ Ou seja, seu objetivo era o de conscientizar jovens de todo o país a respeito de questões caras a toda a sociedade, em especial à comunidade LGBT. Antes, em 2011, também por pressão da mesma bancada religiosa, o Governo já havia suspendido a distribuição de material educativo elaborado pelo Ministério da Educação e que também visava a criar uma política educacional contrária à homofobia nas escolas. ${ }^{8}$

Nos dois casos, argumentos morais compartilhados por amplos setores da sociedade brasileira e com representação também ampla no Congresso Nacional impediram a produção de

conhecimento e de um debate necessário nas escolas sobre uma importantíssima política pública, sendo o Brasil o líder mundial de assassinato de transexuais. ${ }^{9}$ É importante enfatizar a representantividade de tal postura perante o parlamento e parte expressiva da sociedade para demonstrar que se trata de questões que importam quando se considera a moral comunitária (no caso brasileiro, fortemente religiosa) e de crenças que se habilitam a um debate publico que encontra fundamento, para alguns, na própria definição constitucional de família (art. 226 da Constituição Federal). Ou seja, não se cuida de preferências pessoais compartilhadas por parcelas insignificantes da sociedade e que não possam encontrar algum apoio no ordenamento jurídico, o que indica que estamos aqui no campo da moral intersubjetiva e não no campo de meras preferências pessoais isoladas.

\section{Estratégias de Rebaixamento do Corpo: Eugenia e Vidas Indignas de serem Vividas}

\footnotetext{
7 https://oglobo.globo.com/brasil/governo-federal-recolhe-kit-educativo-anti-homofobia-7866048. Acessado em $02 / 10 / 18$.

$8 \quad$ http://g1.globo.com/educacao/noticia/2011/05/dilma-rousseff-manda-suspender-kit-anti-homofobia-dizministro.html. Acessado em 02/10/18.

${ }^{9}$ O Brasil matou ao menos 868 travestis e transexuais nos últimos oito anos, o que o deixa, disparado, no topo do ranking de países com mais registros de homicídios de pessoas transgêneras. $\mathrm{O}$ dado, publicado pela ONG Transgender Europe (TGEu) em novembro de 2016, é assustador, mas não representa novidade para essa parcela quase invisível da sociedade brasileira, que precisa resistir a uma rotina de exclusão e violência (Fonte: http://especiais.correiobraziliense.com.br/brasil-lidera-ranking-mundial-de-assassinatos-de-transexuais, acessado em 02/10/18).
} 
Na tradição, os questionamentos a respeito do homem não encontram uma única solução, mas, de um modo geral, as tentativas de resposta gravitarão em torno de três perspectivas principais, a saber, a aristotélica, que toma o homem como o elemento de referência de todos os demais seres da natureza; a teocêntrica, que fez carreira no período medieval e que considera o homem uma imagem de Deus, tal como se vê nas escrituras; e a antropocêntrica, inaugurada pela modernidade - por Descartes e Kant, em especial - e que alça o homem, pela primeira vez, à condição de sujeito, ou seja, um ser racional e livre.

Dentre as concepções de homem, a que o caracteriza enquanto um ser racional e livre, ou seja, dotado de vontade e liberdade (homo volens), é a que mais largamente foi acolhida pela civilização ocidental, cuidando-se, a razão, de um elemento que supostamente distinguiria o homem dos outros seres. Partindo da premissa de que se Deus é "livre", também o homem, criado à sua imagem e semelhança, é um ser livre ("livre-arbítrio"), cuida-se de uma invenção, a um só tempo, do cristianismo e da modernidade.

Com esta concepção rivaliza a concepção do homem enquanto corpo (homo somaticus), locus de uma vontade determinada por elementos externos (heteronomia), ou seja, pelos desejos e pelas paixões. Para Le Goff, o corpo foi esquecido pela história e pelos historiadores, é o “impensado da civilização ocidental”, uma vez que, à exceção de alguns poucos autores, "o modo de vestir, de morrer, de se alimentar, de trabalhar, de morar, de habitar sua carne, de desejar, de sonhar, de rir ou de chorar não atingiu o estatuto de objeto digno de interesse histórico" (LE GOFF, 2006, p. 15). Tal esquecimento representa o estatuto conferido ao corpo pela modernidade, já com Descartes, que, a partir do cogito e da concepção hierarquizada entre corpo e mente, considerava possível a existência da alma, isto é, da mente, independentemente da existência do corpo, mera extensão não pensante, sendo a essência do homem unicamente o pensar. $^{10}$

Como soa intuitivo, o que está em jogo aqui é um dos fundamentos centrais da religião (pecado) e da moral (esvaziamento das paixões e da experiência, moral racional universal), ou

\footnotetext{
10 “(...) sou uma coisa que pensa, ou uma substância cuja essência toda ou natureza é somente pensar. E, embora talvez (ou melhor, certamente, como logo o direi) eu tenha um corpo ao qual sou muito estreitamente conjunto, não obstante, porque de um lado tenho uma ideia clara e distinta de mim mesmo, na medida em que sou apenas uma coisa que pensa e não extensa, e que, do outro, tenho uma ideia distinta do corpo, na medida em que ele é apenas uma coisa extensa e que não pensa, é certo que esse eu, ou seja, minha alma, pela qual sou o que sou, é inteira e verdadeiramente distinta de meu corpo e pode ser ou existir sem ele". (DESCARTES, 2005, pp. 117-118)
} 
seja, a disputa, de um lado, pela hierarquia entre mente e corpo, com prevalência da mente, e, por outro (do lado das minorias), a reivindicação do corpo enquanto plataforma de exercício da liberdade (gênero, identidade e orientação sexual etc).

As estratégias de rebaixamento do corpo vão encontrar terreno fértil em sociedades em que as teses eugenistas do início do século passado floresceram, as quais, por seus conteúdos aparentemente "científicos" e "neutros", operam no registro da racionalização do ódio.

É o caso da sociedade brasileira, que nas décadas de 20 a 40 do Século XX implementou uma rigorosa política de "branqueamento" de seu povo, inclusive através de uma política imigratória excludente. Como apontado pelas pesquisas sobre o tema, o Brasil mergulhou fundo na difusão da "ciência" eugênica: em janeiro de 1918 o médico Renato Kehl cria a Sociedade Eugênica de São Paulo, o primeiro passo decisivo de organização dos estudos de eugenia na América Latina (STEPAN, 2005, p. 55); em 1922, é criada a Liga Brasileira de Higiene Mental, no Rio de Janeiro, que tinha por objetivo modernizar o atendimento aos doentes mentais, numa

clara associação entre eugenia e psiquiatria, o que viria a ocorrer em vários outros países latinoamericanos e associaria o tema da eugenia aos problemas de criminalidade, delinquência juvenil e prostituição, "patologias" dos pobres e da população mestiça e negra (STEPAN, 2005, p. 58); em 1929 ocorre, também no Rio de Janeiro, o primeiro Congresso Brasileiro de Eugenia, no qual foram discutidos temas relativos ao matrimônio e eugenia, educação eugênica, proteção da nacionalidade, tipos raciais, importância dos arquivos genealógicos, imigração japonesa, campanhas antivenéreas, tóxicos e eugenia, tratamento dos doentes mentais e proteção à infância e à maternidade (KOIFMAN, 2012, pp. 75-76); no mesmo ano, o médico Renato Kehl inicia a publicação do jornal "Boletim de Eugenía", de tiragem mensal; em 1931 cria-se a Comissão Central Brasileira de Eugenia, presidida por Renato Kehl e composta por Eunice Penna Kehl (secretária e esposa de Kehl), Belisário Penna, Gustavo Lessa, Ernani Lopes, Porto-Carrero, Cunha Lopes, Salvador de Toledo Piza Junior, Octavio Domingues, Achiles Lisboa e Pacheco Caetano Coutinho. Tais movimentos iriam refletir, um pouco mais tarde, na legislação do Estado Novo sobre imigração (Decreto-lei n. 3.175/41) e também na Constituição de 1934, que estabeleceu sistema de cotas de imigração de modo a restringir a entrada de novos imigrantes japoneses (KOIFMAN, 2012, p. 77).

Além disso, a eugenia entre nós abarcou aspectos relacionados à sexualidade e à higiene, ou seja, não apenas a genética e a seleção natural, como entre os europeus, sendo comumente 
associada a projetos de higiene social (KOIFMAN, 2012, p. 72-74). Em tal visão, a miscigenação brasileira produziria "degenerescência" e "má-formação", do que seriam exemplos privilegiados os "aleijados ou mutilados", os "indigentes, vagabundos, ciganos e congêneres", os "alcoolistas ou toxicômanos", os de "conduta manifestamente nociva à ordem pública, à segurança nacional ou à estrutura das instituições", os que "se entreguem à prostituição ou a explorem, ou tenham costumes manifestamente imorais" etc. ${ }^{11}$ A interpretação dos efeitos de nossa mestiçagem eram

corroborados por eugenistas europeus e norte-americanos, que viam na América Latina, e especialmente no Brasil, exemplos eloquentes de que os mestiços não conseguiriam produzir uma "alta civilização" capaz de "desenvolvimento progressivo" (STEPAN, 2005, p. 53).

Nesse quadro as preocupações com a família, especialmente com as crianças e as mulheres, ocupavam um lugar de destaque. Como percebido por STEPAN,

\begin{abstract}
"As classes médias latino-americanas, antiquadas e formalmente católicas, veneravam a família tradicional como a instituição fundamental para uma boa sociedade. Nas primeiras décadas do Século XX, essa família tradicional parecia cada vez mais ameaçada, seja pela crescente presença das mulheres nos locais de trabalho, seja pelos novos costumes sexuais trazidos pela modernidade e pela imigração, pela prostituição, a prole ilegítima, os abortos ilegais e o alcoolismo que acompanharam a crescente industrialização, as migrações internas, a urbanização e a pauperização. Uma das respostas possíveis ante os dilemas postos por um corpo político doente constituía-se em sanear, moralizar e eugenizar a família" (STEPAN, 2005, p. 52). ${ }^{12}$
\end{abstract}

$11 \mathrm{O}$ art. $1^{\circ}$ Decreto-Lei n. 406/38 (Estado Novo) assim dispunha: Art. $1^{\circ}$ Não será permitida a entrada de estrangeiros, de um ou outro sexo: I - aleijados ou mutilados, inválidos, cégos, surdos-mudos; II - indigentes, vagabundos, ciganos e congêneres; III - que apresentem afecção nervosa ou mental de qualquer natureza, verificada na forma do regulamento, alcoolistas ou toxicomanos; IV - doentes de moléstias infecto-contagiosas graves, especialmente tuberculose, tracoma, infecção venérea, lepra e outras referidas nos regulamentos de saúde pública; V - que apresentem lesões orgânicas com insuficiência funcional; VI - menores de 18 anos e maiores de 60, que viajarem sós, salvo as exceções previstas no regulamento; VII - que não provem o exercício de profissão lícita ou a posse de bens suficientes para manter-se e às pessoas que os acompanhem na sua dependência; VIII - de conduta manifestamente nociva à ordem pública, è segurança nacional ou à estrutura das instituições; IX - já anteriormente expulsos do país, salvo si o ato de expulsão tiver sido revogado; X condenados em outro país por crime de natureza que determine sua extradição, segundo a lei brasileira; XI que se entreguem à prostituição ou a explorem, ou tenham costumes manifestamente imorais. Parágrafo único. A enumeração acima não exclue o reconhecimento de outras circunstâncias impeditivas, não se aplicando aos estrangeiros que vierem em caráter temporário o disposto nos incisos I, V e VI”. O Decreto-lei n. 3.010/38 dispunha em sentido semelhante (art. 114).

${ }^{12}$ Stepan considera que a linha neolamarckiana teria sido a predileta dos brasileiros, já que mantinha abertas as possbilidades de regeneração e um amplo espaço para a ação moralizadora, além de encaixar-se bem na doutrina católica (apud KOIFMAN, 2012, p. 78). 
$\mathrm{Ou}$ seja, parece claro, a partir desse rápido inventário histórico, que eugenia e moral sempre andaram juntas entre nós. E, ao contrário do que se possa supor, tais "fantasmas" eugênicos não foram completamente erradicados de nossa sociedade e das práticas institucionais contemporâneas, inclusive das práticas do sistema de justiça. E é previsível que seja assim, pois datam de menos de cem anos.

A demonstrar tal afirmação bastaria mencionar recente ação ajuizada pelo Ministério Público de São Paulo contra a moradora de rua Janaína Aparecida Quirino e a Prefeitura Municipal de Mococa, através da qual se pleiteava, contra os requisitos previstos em lei, ${ }^{13}$ a

realização forçada de procedimento de laqueadura. $\mathrm{O}$ argumento de proteção da dignidade humana foi invocado - como é comum em casos semelhantes - e as características pessoais da ré não deixam qualquer dúvida a respeito das motivações eugenistas: mulher pobre e negra, usuária de droga, moradora de rua, mãe de prole numerosa. O Ministério Público de São Paulo alegou, em seu pedido, que:

${ }^{13}$ Lei 9263/96 (Planejamento familiar):

“Art. $2^{\circ}$ Para fins desta Lei, entende-se planejamento familiar como o conjunto de ações de regulação da fecundidade que garanta direitos iguais de constituição, limitação ou aumento da prole pela mulher, pelo homem ou pelo casal.

Parágrafo único - É proibida a utilização das ações a que se refere o caput para qualquer tipo de controle demográfico.

(...)

Art. 10. Somente é permitida a esterilização voluntária nas seguintes situações:

I - em homens e mulheres com capacidade civil plena e maiores de vinte e cinco anos de idade ou, pelo menos, com dois filhos vivos, desde que observado o prazo mínimo de sessenta dias entre a manifestação da vontade e o ato cirúrgico, período no qual será propiciado à pessoa interessada acesso a serviço de regulação da fecundidade, incluindo aconselhamento por equipe multidisciplinar, visando desencorajar a esterilização precoce; II - risco à vida ou à saúde da mulher ou do futuro concepto, testemunhado em relatório escrito e assinado por dois médicos.

$\S 1^{\circ}$ É condição para que se realize a esterilização o registro de expressa manifestação da vontade em documento escrito e firmado, após a informação a respeito dos riscos da cirurgia, possíveis efeitos colaterais, dificuldades de sua reversão e opções de contracepção reversíveis existentes.

$\S 2^{\circ}$ É vedada a esterilização cirúrgica em mulher durante os períodos de parto ou aborto, exceto nos casos de comprovada necessidade, por cesarianas sucessivas anteriores.

$\S 3^{\circ}$ Não será considerada a manifestação de vontade, na forma do $\S 1^{\circ}$, expressa durante ocorrência de alterações na capacidade de discernimento por influência de álcool, drogas, estados emocionais alterados ou incapacidade mental temporária ou permanente.

$\S 4^{\circ}$ A esterilização cirúrgica como método contraceptivo somente será executada através da laqueadura tubária, vasectomia ou de outro método cientificamente aceito, sendo vedada através da histerectomia e ooforectomia. $\S 5^{\circ} \mathrm{Na}$ vigência de sociedade conjugal, a esterilização depende do consentimento expresso de ambos os cônjuges.

$\S 6^{\circ}$ A esterilização cirúrgica em pessoas absolutamente incapazes somente poderá ocorrer mediante autorização judicial, regulamentada na forma da Lei”. 


\begin{abstract}
"Janaína é pessoa hipossuficiente, apresenta grave quadro de dependência química, sendo usuária contumaz de álcool e outras substâncias entorpecentes; por tal motivo, foi acompanhada por órgãos da rede protetiva, como o CAPS $\mathrm{AD}$, e já esteve internada compulsoriamente diversas vezes em instituições próprias ao tratamento de sua drogadição; a última ação ajuizada neste sentido, inclusive, é a de número 1002667-70.2016.8.26.0360, em trâmite perante a $2^{\mathrm{a}}$ Vara Judicial da Comarca, oportunidade em que ela teve sua internação decretada e permaneceu sob tratamento na Fundação Espírita "Américo Bairral Instituto Bairral de Psiquiatria, na cidade de Itapira/SP, no período de 14/10/2016 a 30/12/2016; (...) ela já é mãe de cinco filhos (Felipe, Maria Rita, Luan Gabriel, Santiago Henrique e Antônia Eduarda), todos menores, que já estiveram na Casa
\end{abstract}

de Acolhimento Bethânia, na cidade de Mococa, sendo certo que não ostenta condições de prover as necessidades básicas de seus rebentos, além de colocálos, frequentemente, em potencial risco em razão do uso de álcool e outras drogas; dessa forma, foi recomendada pelos equipamentos de saúde e de assistência social do Município a realização de laqueadura tubária como método contraceptivo; ela constantemente é encontrada perambulando pelas ruas da cidade com claros sinais de uso abusivo de álcool e drogas; em determinados momentos, ela manifesta vontade em realizar o procedimento de esterilização; noutros, demonstra desinteresse ao não aderir aos tratamentos e ao descumprir orientações dos equipamentos da rede protetiva". ${ }^{14}$

Como se vê dos autos processuais, o pedido foi deferido liminarmente pelo Juízo de primeira instância, não obstante tenha sido reformado, a destempo (a irreversível cirurgia já havia sido realizada), pelo Tribunal de Justiça de São Paulo. ${ }^{15}$ O voto do Desembargador Leonel Costa é bastante duro ao mencionar que o caso seria o de uma "esterilização compulsória, eugênica e demográfica" e ressalta que a ré sequer foi ouvida pessoalmente pelo Promotor de Justiça e pelo Juiz, uma prudência mínima que se impunha dada a gravidade do pedido. ${ }^{16}$

14 Extraído do relatório do acórdão prolatado na Apelação Cível n. 1001521-57.2017.8.26.0360 TJSP(https://www.jota.info/wp-content/uploads/2018/06/f3a4927c997cc4c0a5f5c864cfd3db9b.pdf, acessado em 04/10/18).

${ }^{15}$ Apelação no 1001521-57.2017.8.26.0360. Apelante: Prefeitura Municipal de Mococa. Apelado: Ministério Público do Estado de São Paulo Interessado: Janaina Aparecida Quirino. Comarca: Mococa.

Ementa: “AÇÃO CIVIL PÚBLICA. Pretensão do Ministério Público voltada a compelir o Município a realizar cirurgia de laqueadura em dependente química (...). Inadmissibilidade, diante do ordenamento jurídico pátrio, da realização compulsória de tal procedimento. Pleno e autônomo consentimento não manifestado pela requerida aos órgãos da rede protetiva. Interdição judicial, outrossim, que não foi decretada a qualquer tempo. Lei $n^{\circ}$ 9.263/96 que limita até mesmo a esterilização voluntária (v. art. 10). Apelo da Municipalidade provido." ${ }^{16}$ Já o Desembargador Bandeira Lins, também em duro voto, enfatiza que "a ideia de que em nome de alguma lei se pudesse proceder de forma diversa implica despossuir a pessoa dela mesma: em semelhante perspectiva, a pessoa se coisifica; e longe de ser sujeito de direitos, passa a ser, como a propriedade sobre objetos externos, uma função social, que, mal desempenhada, dá azo à investidura de vontade alheia em domínio pleno sobre o corpo que fora da pessoa" (https://www.jota.info/wpcontent/uploads/2018/06/f3a4927c997cc4c0a5f5c864cfd3db9b.pdf, acessado em 04/10/18). 
Parece-nos que este exemplo é uma demonstração bastante eloquente de que a eugenia ainda habita os corações e as mentes de nossa sociedade, que sempre demostrou especial fascínio pelo controle de natalidade das "raças inferiores" e que considera que algumas vidas, a partir de suas lentes morais, são indignas de serem vividas.

\section{Subjetividades Contábeis}

De acordo com a Síntese de Indicadores Sociais do IBGE, divulgada em dezembro de 2017, 25,4\% da população brasileira vivia em situação de pobreza em 2016, de acordo com o critério adotado pelo Banco Mundial, que considera pobre quem ganha menos do que US\$ 5,5 por dia nos países em desenvolvimento (o que equivale a uma renda domiciliar per capita de R $\$$ 387 por mês, ao considerar a conversão pela paridade de poder de compra). O mesmo levantamento aponta que a situação é mais grave entre os 7,4 milhões de moradores de domicílios onde vivem mulheres pretas ou pardas sem cônjuge com filhos até 14 anos. Desses, $64,0 \%$ estavam abaixo dessa faixa de renda. ${ }^{17}$ Este último dado demonstra a correlação entre problemas de distribuição e de reconhecimento, pois mistura pobreza com questões de gênero e de raça.

Justamente para dar conta de tal problema, o Brasil criou, em 2003, o Programa Bolsa Família, que tem por objetivo garantir uma renda mínima para famílias em situação de pobreza ${ }^{18}$ e que o Relatório de Desenvolvimento Humano 2015, do Programa das Nações Unidas para o Desenvolvimento (Pnud), destacou como essencial para a redução da pobreza multidimensional, por promover acesso à saúde, educação e assistência social. ${ }^{19}$

De notar-se que dentre os objetivos de nossa República figuram a erradicação da pobreza e da marginalização e a redução das desigualdades sociais e regionais, além da construção de

17 In: https://agenciadenoticias.ibge.gov.br/agencia-noticias/2012-agencia-de-noticias/noticias/18825-umquarto-da-populacao-vive-com-menos-de-r-387-por-mes. Acessado em 09/10/18.

18 “A população alvo do programa é constituída por famílias em situação de pobreza ou extrema pobreza. As famílias extremamente pobres são aquelas que têm renda mensal de até $\mathrm{R} \$ 89,00$ por pessoa. As famílias pobres são aquelas que têm renda mensal entre $\mathrm{R} \$ 89,01$ e R $\$ 178,00$ por pessoa. As famílias pobres participam do programa, desde que tenham em sua composição gestantes e crianças ou adolescentes entre 0 e 17 anos" (Fonte:. http://www.caixa.gov.br/programas-sociais/bolsa-familia/Paginas/default.aspx. Acessado em 09/10/18).

${ }_{19} \quad$ http://www.brasil.gov.br/cidadania-e-justica/2015/12/onu-destaca-bolsa-familia-como-essencial-parareducao-da-pobreza, acessado em 09/10/18. 
uma sociedade livre, justa e solidária (art. $3^{\circ}$, caput e incisos I e III da Constituição Federal). Nessa linha, de acordo com o texto Constitucional, políticas de assistência social são um direito fundamental, não um favor: é o que estabelece o art. $6^{\circ}$ da Carta, ao estatuir que "são direitos sociais a educação, a saúde, a alimentação, o trabalho, a moradia, o transporte, o lazer, a segurança, a previdência social, a proteção à maternidade e à infância, a assistência aos

desamparados, na forma desta Constituição", bem como seu art. 203, ao afirmar que "a assistência social será prestada a quem dela necessitar, independentemente de contribuição à seguridade social, e tem por objetivos a proteção à família, à maternidade, à infância, à adolescência e à velhice; o amparo às crianças e adolescentes carentes; a habilitação e reabilitação das pessoas portadoras de deficiência e a promoção de sua integração à vida comunitária; a garantia de um salário mínimo de benefício mensal à pessoa portadora de deficiência e ao idoso que comprovem não possuir meios de prover à própria manutenção ou de tê-la provida por sua família”, dentre outros.

Embora seja um direito fundamental amparado pelo texto constitucional, a assistência social materializada pela fruição de uma renda mínima não é assim percebida pelas famílias "beneficiárias". Muito ao contrário, o recebimento de renda governamental por intermédio do Programa Bolsa Família é acompanhado por uma série de julgamentos morais e de sentimentos negativos de vergonha e humilhação nutridos pelos contemplados, por seus vizinhos e até pelos atores institucionais responsáveis pelo programa.

É o que demonstra primorosa pesquisa realizada por MARINS, que, entre fevereiro e maio de 2011, realizou setenta entrevistas com famílias beneficiárias, famílias não beneficiárias e atores institucionais (assistentes sociais, professores, agentes de saúde etc) de um bairro pobre do Município de Itaboraí. Os resultados indicam que ser "beneficiário" do programa produz um processo de profunda estigmatização perante a comunidade e os atores institucionais, ou seja, julgamentos morais dos beneficiários enquanto "acomodados", "preguiçosos", "vagabundos", “aproveitadores" etc, num processo de classificação moral extremamente humilhante (MARINS, 2017, pp. 165 e ss). Há, segundo a pesquisa, desde o julgamento sobre a forma de utilização do valor do programa ("gastam dinheiro com cachaça", "deixam as crianças largadas" etc) até constrangimentos no interior das agências bancárias onde os valores são sacados. A este propósito, o depoimento da beneficiária Carla (nome fictício) sobre o cartão de saque do Bolsa Família é expressivo: 


\begin{abstract}
"Tá lá escrito, né? Combate à fome. E aí, a gente fica envergonhada porque elas acham que somos esfomeados. As pessoas ficam sem graça por estar no Programa Fome Zero, né? Tipo assim, quando a moça atende o 0800, a gente se sente com vergonha. Ainda bem que ela não nos vê, só ouve (risos)" (MARINS, 2017, p. 185).
\end{abstract}

As próprias entrevistas feitas para o cadastramento no programa são atravessadas por julgamentos morais de assistentes sociais e demais atores institucionais, os quais, na percepção captada pela pesquisa, acham que os beneficiários estão mentido sobre suas situações pessoais de renda, situação familiar etc, o que reforça a ideia de que se trataria não de direito, mas sim de um "favor". Isso faz com que os beneficiários, no ato de entrevista, muitas vezes incorporem o papel de "vítimas" a fim de serem acreditados, ou seja, para que não sejam injustamente tachados de enganadores e mentirosos (MARINS, 2017, p. 172).

O que está em jogo é a ideia de "fracasso" em conseguir prover o seu sustento e de sua família por meios próprios, ou seja, pelo trabalho e não por meio de uma ajuda governamental. Aqui a moral atua como um elemento que dissolve a percepção da assistência social como um direito, um verdadeiro obstáculo psicológico que muitas vezes gera o isolamento do indivíduo de suas relações sociais, pois ele prefere se "esconder" em casa a ser reconhecido pela vizinhança como um "fracassado". Mas mesmo no âmbito familiar as relações passam por julgamentos morais (ou pelo menos pela imanginação de que tais julgamento ocorram) dos cônjuges, filhos, sogros e sogras etc.

Talvez se possa investir nas indagações sobre o modo de ser do brasileiro, seu temperamento, para justificar os problemas aqui identificados, isto é, indagações sobre os traços antropológicos e sociológicos que expliquem essa postura da cidadania frente ao Estado (e viceversa). Parece-nos, contudo, que os problemas apontados pela pesquisa de MARINS conectamse com as exigências que brotam de uma nova subjetividade dada pelo neoliberalismo, isto é, às exigências de uma subjetividade em que todos devem se ver (e serem vistos) como subjetividades contábeis e financeiras, na feliz expressão de Laval \& Dardot (LAVAL \& DARDOT, 2016, pp. 16 e 30$)$. 
Referidos autores, retomado os temas explorados por Foucault no "Nascimento da Biopolítica" (1978/1979), sustentam que o neoliberalismo é um tipo de racionalidade política que tem como característica principal a generalização da concorrência como norma de conduta e da empresa como modelo de subjetivação e que foram os Estados que introduziram e universalizaram na economia, na sociedade e até neles próprios a lógica da concorrência e o modelo da empresa (LAVAL \& DARDOT, 2016, pp. 17-19). Além disso, não se trata apenas de

uma racionalidade que destrói regras, instituições e direitos, mas sim de uma racionalidade que produz certos tipos de relações sociais, certas maneiras de viver informadas pela competitividade e pelo individualismo (LAVAL \& DARDOT, 2016, pp. 16 e 30). Trata-se, portanto, de "produzir uma relação do sujeito individual com ele mesmo que seja homóloga à relação do capital com ele mesmo ou, mais precisamente, uma relação do sujeito com ele mesmo como um 'capital humano' que deve crescer indefinidamente, isto é, um valor que deve valorizar-se cada vez mais" (LAVAL \& DARDOT, 2016, p. 31), um padrão que as populações vulneráveis, de um modo geral, não estão em condições de atender.

$\mathrm{Na}$ construção desse novo sujeito, o indivíduo-empresa, o conceito liberal de mérito cumpre um papel fundamental. Por mérito geralmente se entende o esforço feito em busca do atingimento de uma meta individual, sobretudo o sucesso profissional, o que dependeria de uma força psicológica (a força do querer, a "força de vontade") de que todos nós (ou quase todos) seríamos portadores, uma força empreendedora, enfim. Fatores externos, como, por exemplo, ser oriundo de uma família economicamente sustentável e ter frequentado boas escolas, não contam nesse novo ambiente do mérito, o que abre largos espaços para o julgamento moral dos "inaptos" de todos os tipos, isto é, dos "acomodados", dos "preguiçosos" etc, que inclusive encontrariam expressões regionais bastante difundidas entre nós (os nordestinos e os indígenas, por exemplo, seriam "preguiçosos").

Como dirão Laval \& Dardot,

\footnotetext{
"Além do modo de gestão e suas ferramentas técnicas, a relação entre governantes e governados é radicalmente subvertida. De fato, é toda a cidadania, tal como se construiu nos países ocidentais desde o Século XVIII, que é questionada até em suas raízes. É o que se vê em especial pelo
} 
questionamento prático de direitos até então ligados à cidadania, a começar pelo direito à proteção social, que foi historicamente estabelecido como consequência lógica da democracia política. 'Nada de direitos se não houver contrapartidas' é o refrão para obrigar os desempregados a aceitar um emprego inferior, para fazer os doentes ou os estudantes pagarem por um serviço cujo benefício é visto estritamente como individual, para condicionar os auxílios concedidos à família às formas desejáveis de educação parental. (...) A figura do 'cidadão' investido de uma

responsabilidade coletiva desaparece pouco a pouco e dá lugar ao homem empreendedor. Este não é apenas o 'consumidor soberano' da retórica neoliberal, mas o sujeito ao qual a sociedade não deve nada, aquele que 'tem de se esforçar para conseguir o que quer' e deve 'trabalhar mais para ganhar mais" (LAVAL \& DARDOT, 2016, pp. 380-381).

Daí se segue que o gozo de direitos passa a depender do mérito e de contrapartidas, o que contaria, inclusive, com respaldo na moral cristã (ou pelo menos numa certa apropriação da moral cristã): "se alguém não quer trabalhar, também não coma" (II Tessalonicenses 3:10).

\section{Conclusão}

Boa parte das discussões sobre os direitos das minorias se prende ainda ao debate sobre as dimensões do Princípio da Igualdade, ou seja, as tensões entre a igualdade em sentido formal ou isonomia ("todos são iguais perante a lei"), fruto das revoluções liberais do Século XVIII, mas ainda insuficiente à defesa das minorias, e a igualdade em sentido material, que requer do Estado uma atuação (prestações positivas) em benefício de grupos vulneráveis, garantindo-lhes o acesso aos bens socialmente produzidos. Essa última perspectiva (igualdade material) possuiria dois critérios, a saber, o da redistribuição e a do reconhecimento: a igualdade-redistribuição demandando a distribuição ou redistribuição dos bens e ônus, vantagens e desvantagens sociais entre grupos, ou seja, no cenário do Estado Social de Direito, a redução das desigualdades e realização da justiça social, assegurando independência e a voz de indivíduos e grupos (por exemplo, através de programas de renda mínima, programas de assistência social, programas de habitação para população de baixa renda, ações afirmativas etc); já o critério da igualdadereconhecimento envolveria demandas por reconhecimento de igual respeito na relação com outros sujeitos e grupos sociais, ou seja, o reconhecimento da diferença, ou, como dirá Fraser (FRASER, 2007, pp. 108 e ss.), o reconhecimento de membros de um grupo como parceiros 
integrais na interação social (igualdade orientada pelos critérios de gênero, orientação sexual, raça e etnia). ${ }^{20}$ A rigor, é falsa a dicotomia entre os dois critérios uma vez que em muitos casos

os dois tipos de políticas públicas (redistribuição e reconhecimento) devem ser combinados, o que ocorre relativamente às "coletividades bivalentes" (FRASER, 2006, p. 233), diferenciadas tanto em virtude da estrutura econômico-política quanto da estrutura cultural-valorativa da sociedade (subordinação econômica e subordinação cultural).

O que propomos no presente trabalho é discutir os direitos das minorias para além de tais importantes questões, colocando em xeque o fundamento moral enquanto plataforma de reivindicação e criação de direitos.

É certo que a moral que interdita os direitos das minorias é conservadora, retrógrada, e sempre foi desprezada pelos liberais igualitários como sendo uma moral indigna de ingressar na arena do debate público (uma moral "indefensável" ou "inválida"). Haveria, a partir de tal visão, uma moral "boa" (a moral liberal) e outra "ruim", "má", geralmente associada a movimentos de extrema-direita, ao fascismo e a povos incivilizados. Mas a moral "ruim" ingressou com uma força colossal, aliou-se ao mercado e elegeu Trump (na pátria liberal), varreu a Europa e chegou com força entre nosotros. A má notícia é que se cuida de uma moralidade que pode existir naturalmente num ambiente neoliberal, como observado por Löwy:

\begin{abstract}
"A análise "clássica" de esquerda sobre o fascismo o explica essencialmente como um instrumento do grande capital para esmagar a revolução e o movimento dos trabalhadores. Com base nessa premissa, algumas pessoas da esquerda argumentam que já que hoje o movimento dos trabalhadores está muito enfraquecido e a ameaça revolucionária não existe, o grande capital não teria interesse em apoiar movimentos da extrema-direita, de modo que o risco de uma ofensiva marrom não existiria. Esta é, uma vez mais, uma leitura economicista que não leva em conta a autonomia de nenhum fenômeno político. Os eleitores podem, na verdade, escolher um partido que não tem o apoio da grande burguesia. Além disso, esse estreito argumento econômico parece ignorar o fato de que o grande capital pode acomodar-se em todos os tipos de regimes politicos sem muito exame de consciência" (LÖWY, 2015, pp. 658-659).
\end{abstract}

\footnotetext{
${ }^{20}$ Problemas relacionados ao não-reconhecimento (ser considerado invisível pelas práticas de uma determinada cultura; privação da possibilidade de participação na vida social em pé de igualdade); desrespeito (ser difamado habitualmente em interações cotidianas ou representações públicas estereotipadas) e dominação cultural (estar sujeito a padrões de interpretação e comunicação associados a cultura estranha ou hostil).
} 
A observação de Löwy nos alerta para o fato de que a aliança aparentemente indissolúvel entre a boa moral libertária e o capitalismo (neoliberalismo) é um mito e um erro de análise, uma vez que o modelo neoliberal de racionalidade (e de economia) pode facilmente divorciar-se de qualquer "exame de consciência".

Por isso é necessário contestar o estatuto legitimador da moral em si, de suas artimanhas de hierarquização entre mente e corpo (e de apagamento do corpo), seus processos seletivos meritórios (fortemente incentivados pelo liberalismo), seu desprezo pelos "anormais, "inválidos", "vagabundos", "preguiçosos" e sua fácil acomodação às novas exigências neoliberais. Ou seja, mesmo que de uma qualidade inferior, trata-se, ainda assim, da velha moral que precisa ser destronada.

No campo jurídico, essa "moral menor", mas altamente destrutiva, encontra terreno fértil no atual ambiente neoconstitucionalista, que investe no casamento entre direito e moral e no ativismo judicial. O problema é que nada garante que esse casamento seja fiador dos direitos fundamentais. Muito pelo contrário, é entre insuspeitos neoconstitucionalistas, sobretudo os que se consideram partícipes de uma "vanguarda iluminista", que muitas vezes encontraremos duros discursos contra as liberdades (a presunção de inocência foi a vítima mais recente no Brasil, numa estatística que demonstra que os homicídios contra a Constituição, praticados sobretudo por seu guardião, estão em escala ascendente).

Enfim, os direitos das minorias não são conquistas morais da humanidade. São, antes, conquistas políticas de movimentos sociais que escrevem a história social dos direitos humanos: o movimento negro norte-americano por direitos civis, na década de sessenta; os movimentos feministas pelo sufrágio; os movimentos atuais dos gays e lésbicas de todo o mundo por respeito etc. Por isso os direitos das minorias devem ser escritos e reescritos todos os dias, não são dados, não são a priori morais.

THE MORAL FOUNDATION OF HUMAN RIGHTS AS AN OBSTACLE TO THE IMPLEMENTATION OF MINORITIES RIGHTS 
Abstract: The purpose of this paper is to question the moral foundation as a platform for the claim and creation of minorities rights, that is to say, the widespread idea that the normative force of human rights will seek its foundation in moral. In addition to all the problems that a moral

approach to rights raises, specifically in the area of minority rights it is precisely the moral that will represent the most powerful obstacle to its implementation, because: - the moral and the abstract universal concepts to which it connects are epistemological barriers; - many of the rights of minorities find in the body their platform of claim, which morality interdicts through various strategies of depreciation of the body; - in a neoliberal world, the moral argument of merit is articulated with a new rationality that produces systematic competition between individuals, excluding a large number of vulnerable groups and individuals. We start from the premise that minority rights are not the moral achievements of humankind but rather the political achievements of social movements that write the social history of human rights, that is, from the fact that minority rights must be written and rewritten every day, are not a priori moral. Briefly, it is necessary to face the legitimating status of morality itself, beyond the usual discussions about redistribution and recognition. The methodology will consist of bibliographical review on the subject and the analysis of some empirical data, with incursions in the fields of law, philosophy of law and sociology.

Keywords: HUMAN RIGHTS; MORAL; MINORITIES; VULNERABLE PEOPLE.

\section{Referências bibliográficas:}

DARDOT, Pierre \& LAVAL, Christian. A nova razão do mundo. Ensaio sobre a sociedade neoliberal. Tradução de Mariana Echalar. São Paulo: Boitempo, 2016.

DELEUZE, Gilles. Apresentação de Sacher-Masoch. O Frio e o Cruel. Tradução de Jorge Bastos. Rio de Janeiro: Livraria Taurus Editora, 1983. . Espinosa: Filosofia Prática. Tradução de Daniel Lins et alii. São Paulo: Escuta,

2002. 
DESCARTES, René. Meditações Metafísicas. Tradução de Maria Ermantina Galvão. São Paulo: Martins Fontes, 2005.

FOUCAULT, Michel. Nascimento da Biopolítica. Tradução de Eduardo Brandão. São Paulo: Martins Fontes, 2008.

FRASER, Nancy. Da redistribuição ao reconhecimento? Dilemas da justiça numa era "póssocialista”. In: Cadernos de Campo, SP, n. 14/15, 2006, pp. 231-239.

Reconhecimento sem Ética? In: Lua Nova, SP, 70: 101-138, 2007.

HABERMAS, Jürgen. "El Concepto de Dignidade Humana y La Utopía Realista de los Derechos Humanos”. In: Diánoia, Vol. LV, número 64, Maio de 2010, pp. 3-25.

HÖFFE, Otfried. Immanuel Kant. Tradução de Christian Viktor Hamm e Valerio Rohden. São Paulo: Martins Fontes, 2005. . Justiça Política. Tradução de Ernildo Stein. Petrópolis: Vozes, 1991;

JUBILUT, Liliana Lyra. Itinerários para a proteção das minorias e dos grupos vulneráveis: os desafios conceituais e de estratégias de abordagem. In: Direito à diferença: aspectos teóricos e conceituais da proteção às minorias e aos grupos vulneráveis. Vol. I. Liliana Lyra Jubilut et alii (coords.). São Paulo: Saraiva, 2013, pp. 13-30.

KANT, Immanuel. Fundamentação da Metafísica dos Costumes. Tradução de Paulo Quintela. Lisboa: Edições 70, 2011. . A Metafísica dos Costumes. Tradução de Edson Bini. Bauru: Edipro, 2003.

KOIFMAN, Fabio. Imigrante ideal. São Paulo: Civilização Brasileira, 2012.

LE GOFF, Jacques. Uma História do Corpo na Idade Média. Tradução de Marcos Flamínio Peres. Rio de Janeiro: Civilização Brasileira, 2006.

LÖWY, Michael. Conservadorismo e extrema-direita na Europa e no Brasil. In: Serv. Soc. Soc., São Paulo, n. 124, out./dez. 2015, pp. 652-664.

MARINS, Mani Tebet A. Bolsa Família. Questões de gênero e moralidades. Rio de Janeiro: Editora UFRJ, 2017.

MIAILLE, Michel. Introdução crítica do direito. 3a . Edição. São Paulo: Editorial Estampa, 2005. NINO, Carlos S. Sobre los Derechos Morales. Doxa n. 7, Buenos Aires, 1990, pp. 311-325. 


\section{. Ética e Direitos Humanos. Tradução de Nélio Schneider. São Leopolod: Ed.}

Unisinos, 2011.

SPINOZA, Baruch. Tratado Teológico-Político. Tradução de Diogo Pires Aurélio. São Paulo: Martins Fontes, 2008.

STEPAN, Nancy Leys. A Hora da Eugenia: raça, gênero e nação na América Latina. Rio de Janeiro: Editora Fiocruz, 2005.

Trabalho enviado em 21 de janeiro de 2019

Aceito em 06 de fevereiro de 2020 